Technological University Dublin

DƯBLIN

ARROW@TU Dublin

\title{
Crystal-field Engineering of Ultrabroadband Mid-infrared Emission in Co2+-doped Nano-chalcogenide Glass Composites
}

\author{
Xiasong Lu \\ Harbin Engineering University \\ Runan Zhang \\ Harbin Engineering University \\ Yindong Zhang \\ Harbin Engineering University
}

See next page for additional authors

Follow this and additional works at: https://arrow.tudublin.ie/engscheleart2

Part of the Electrical and Electronics Commons

\section{Recommended Citation}

Lu, X., Zhang, R., Zhang, Y. et al. (2020). Crystal-field engineering of ultrabroadband mid-infrared emission in Co2+-doped nano-chalcogenide glass composites. Journal of the European Ceramic Society, 40(1), pp.103-107. doi:10.1016/j.jeurceramsoc.2019.09.006

This Article is brought to you for free and open access by the School of Electrical and Electronic Engineering at ARROW@TU Dublin. It has been accepted for inclusion in Articles by an authorized administrator of ARROW@TU Dublin. For more information, please contact arrow.admin@tudublin.ie, aisling.coyne@tudublin.ie, gerard.connolly@tudublin.ie.

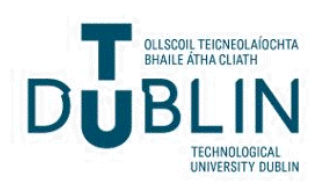




\section{Authors}

Xiasong Lu, Runan Zhang, Yindong Zhang, Shaoqian Zhang, Jing Ren, Lukas Strizik, Thomas Wagner, Gerald Farrell, and Pengfei Wang 


\title{
Crystal-field engineering of ultrabroadband mid-infrared emission in $\mathrm{Co}^{2+}$ - doped nano-chalcogenide glass composites
}

\author{
Xiaosong Lu' ${ }^{\mathrm{a}}$, Runan Zhang ${ }^{\mathrm{a}}$, Yindong Zhang ${ }^{\mathrm{a}}$, Shaoqian Zhang ${ }^{\mathrm{b}}$, Jing Ren ${ }^{\mathrm{a}, *}$, Lukas Strizik ${ }^{\mathrm{c}}$, \\ Tomas Wagner ${ }^{\mathrm{c}, \mathrm{d}}$, Gerald Farrell ${ }^{\mathrm{e}}$, Pengfei Wang ${ }^{\mathrm{a}, \mathrm{f}, *}$ \\ ${ }^{a}$ Key Lab of In-fiber Integrated Optics, Ministry Education of China, Harbin Engineering University, Harbin, 150001, China \\ ${ }^{\mathrm{b}}$ Key Laboratory of Chemical Lasers, Dalian Institute of Chemical Physics, CAS, Dalian, 116023, China \\ ${ }^{\mathrm{c}}$ Department of General and Inorganic Chemistry, Faculty of Chemical Technology, University of Pardubice, Studentska 573, 53210, Pardubice, Czech Republic \\ ${ }^{\mathrm{d}}$ Department of General and Inorganic Chemistry, Faculty of Chemical Technology and Center for Materials and Nanotechnologies, University of Pardubice, Studentska \\ 573, Pardubice, 532 10, Czech Republic \\ e Photonics Research Centre, Dublin Institute of Technology, Kevin Street, Dublin 8, Ireland \\ ${ }^{\mathrm{f}}$ Key Laboratory of Optoelectronic Devices and Systems of Ministry of Education and Guangdong Province, College of Optoelectronic Engineering, Shenzhen University, \\ Shenzhen, 518060, China
}

\section{A R T I C L E I N F O}

\section{Keywords:}

Crystal field engineering

Mid-infrared emission

II-VI crystal

Chalcogenide glass

$\mathrm{Co}^{2+}$

\begin{abstract}
A B S T R A C T
Tunable and ultrabroadband mid-infrared (MIR) emissions in the range of 2.5-4.5 $\mu \mathrm{m}$ are firstly reported from $\mathrm{Co}^{2+}$-doped nano-chalcogenide (ChG) glass composites. The composites embedded with a variety of binary (ZnS, CdS, ZnSe) and ternary (ZnCdS, ZnSSe) ChG nanocrystals (NCs) can be readily obtained by a simple onestep thermal annealing method. They are highly transparent in the near- and mid-infrared wavelength region. Low-cost and commercially available $\mathrm{Er}^{3+}$-doped fiber lasers can be used as the excitation source. By crystalfield engineering of the embedded NCs through cation- or anion-substitution, the emission properties of $\mathrm{Co}^{2+}$ including its emission peak wavelength and bandwidth can be tailored in a broad spectral range. The phenomena can be accounted for by crystal-field theory. Such nano-ChG composites, perfectly filling the 3-4 $\mu \mathrm{m}$ spectral gap between the oscillations of $\mathrm{Cr}^{2+}$ and $\mathrm{Fe}^{2+}$ doped II-VI ChG crystals, may find important MIR photonic applications (e.g., gas sensing), or can be used directly as an efficient pump source for $\mathrm{Fe}^{2+}$ : II-VI crystals which are suffering from lack of pump sources.
\end{abstract}

\section{Introduction}

Much attention has been paid to broadband mid-infrared (MIR) light sources in the wavelength range of $2-5 \mu \mathrm{m}$, covering the important "atmospheric window of transparency", "water absorption band" and "molecular fingerprints" [1]. Since firstly demonstrated by Laura et al in 1996 [2], MIR light sources based on divalent transition metal ions $\left(\mathrm{TM}^{2+}: \mathrm{Cr}^{2+}, \mathrm{Fe}^{2+}\right.$ etc.) doped group II-VI chalcogenide (ChG) crystals (e.g., ZnS, ZnSe etc.) have achieved remarkable progress and become commercially available [3]. The most favorable attributes of $\mathrm{TM}^{2+}$-doped II-VI crystals include but are certainly not limited to that: they have an extremely broad laser-wavelength tuning range $\left(\sim 0.5 \lambda_{0}\right.$, $\lambda_{0}$ is the emission peak wavelength). Such a merit stems from the unique photoluminescence (PL) properties of $\mathrm{TM}^{2+}$ which are extremely sensitive to local crystal-field environment. It has been demonstrated that the PL band positions and correspondingly, the lasing wavelengths of $\mathrm{Cr}^{2+}$ and $\mathrm{Fe}^{2+}$ can be tailored by a solid solution and crystal-field engineering (CFE) approach [4], viz., forming ternary or quaternary ChG crystals by cation and/or anion substitution (scheme figure, Fig. 1) [5-7]. For example, through $\mathrm{Mg}^{2+}$ substitution for $\mathrm{Zn}^{2+}$ in $\mathrm{Zn}_{1-\mathrm{x}} \mathrm{Mg}_{\mathrm{x}} \mathrm{Se}$ crystals, the lasing wavelengths of $\mathrm{Cr}^{2+}$ and $\mathrm{Fe}^{2+}$ dopants can be tuned from 2.2 to $2.6 \mu \mathrm{m}$ [5], and from 4.5 to $5.1 \mu \mathrm{m}$ [6], respectively. Despite that $\mathrm{Cr}^{2+}$ and $\mathrm{Fe}^{2+}$ doped $\mathrm{ChG}$ crystals have enjoyed a great success in covering wide MIR spectral ranges, the $3-4 \mu \mathrm{m}$ wavelength range still remains as a spectral gap waiting for its competitive candidates.

Divalent cobalt ions, when tetrahedrally coordinated in II-VI ChG crystals, show strong PL in the $3-4 \mu \mathrm{m}$ wavelength range, perfectly filling the spectral gap mentioned above [2]. Because of the spectral overlap between $\mathrm{Co}^{2+}$ emission and $\mathrm{Fe}^{2+}$ absorption bands, $\mathrm{Co}^{2+}$ has been proposed as an effective sensitizer for $\mathrm{Fe}^{2+}$ MIR lasing via the $\mathrm{Co}^{2+} \rightarrow \mathrm{Fe}^{2+}$ energy transfer (ET) [8]. Moreover, $\mathrm{Co}^{2+}$ has two strong absorption bands at $\sim 730$ and $1600 \mathrm{~nm}$, which can be potentially

\footnotetext{
* Corresponding authors at: Key Lab of In-fiber Integrated Optics, Ministry Education of China, Harbin Engineering University, Harbin, 150001, China.

E-mail addresses: ren.jing@hrbeu.edu.cn (J. Ren), pengfei.wang@dit.ie (P. Wang).
} 


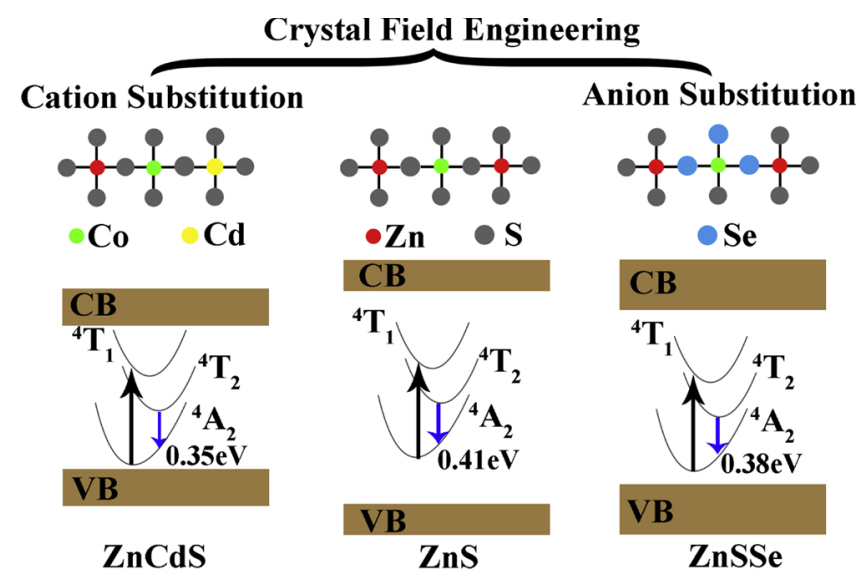

Fig. 1. Scheme of crystal field engineering of $\mathrm{TM}^{2+}$ (e.g., $\mathrm{Co}^{2+}$ ) emission via cation or anion substitution. CB: conduction band; VB: valence band. The indicated energy (in eV) correlates with the emission peak wavelength of $\mathrm{Co}^{2+}$ in the corresponding crystals derived from Fig. 7 shown below.

excited by readily available bulk, fiber or diode lasers. Recently, $\mathrm{Co}^{2+}$ activated II-VI ChG crystals have attracted increasing interest. For example, Chen et al reported broadband MIR emissions upon $808 \mathrm{~nm}$ excitation in $\mathrm{Co}^{2+}$ : ZnSe nanocrystals (NCs) prepared by hydrothermal method [9]. Ali et al observed a MIR emission in a $\mathrm{Co}^{2+}$ doped metalorganic framework glass [10]. For bulk photonic applications, NCs should be incorporated and well protected in an inert host free of undesirable hydroxyl and organic species [10]. However, we have not been aware of any studies pertaining to $\mathrm{Co}^{2+}$ MIR emissions in inorganic glasses, let alone the CFE of the $\mathrm{Co}^{2+}$ emissions [11,12]. The inorganic glasses, when compared to their crystal counterparts, have the following advantages of: 1) feasibility of waveguiding (e.g., by drawing into optical fibers) and thus being potentially free of the detrimental thermal lensing effect [13]; and 2) capability of chip-scale production for integrated optics [1,11].

By the aid of diffusion limited crystallization, we have previously synthesized nanoscale $\mathrm{Cr}^{2+}: \mathrm{ZnS}$ crystals embedded in inorganic Ge-As$S$ ChG glass $[13,14]$. The nano-ChG glass composites thus obtained retain good IR transparency and more importantly show intense ultrabroadband MIR emission of $\mathrm{Cr}^{2+}$ [14]. In this work, an ultrabroadband MIR emission was obtained in a similar type of transparent nano-ChG glass composites embedded with $\mathrm{Co}^{2+}$ : ZnS NCs. It is, however, important to note that by proper adjustment of glass compositions, various $\mathrm{Co}^{2+}$ doped ternary ChG NCs can be thermally grown in the designed ChG glasses for the first time. Those ternary crystals formed due to cation or anion substitution (Fig. 1) impart a variety of crystal-field environments for $\mathrm{Co}^{2+}$. As such, the emission properties including the peak wavelength and bandwidth can be engineered in a broad spectral range.

\section{Experiments}

Samples with the compositions of (in mol.\%) $90 \mathrm{Ge}_{2.5} \mathrm{As}_{1.5} \mathrm{~S}_{6}$ $10 \mathrm{ZnSe}(\mathrm{ZnS}), 90 \mathrm{Ge}_{2.5} \mathrm{As}_{1.5} \mathrm{~S}_{6}-5 \mathrm{ZnSe}-5 \mathrm{CdSe}(\mathrm{ZnCdS}), 90 \mathrm{Ge}_{2.5} \mathrm{As}_{1.5} \mathrm{~S}_{6}$ - 10CdSe (CdS), 90Ge $2.5 \mathrm{As}_{1.5} \mathrm{~S}_{3} \mathrm{Se}_{3}$ - 10ZnSe (ZnSSe), and $90 \mathrm{Ge}_{2.5} \mathrm{As}_{1.5} \mathrm{Se}_{6}-10 \mathrm{ZnSe}$ (ZnSe), all doped with $0.2 \mathrm{~mol} \% \mathrm{CoCl}_{2}$ were prepared by melt-quenching method. Raw materials (Ge, As, S, Se, ZnSe with $5 \mathrm{~N}$-purity, and $\mathrm{CoCl}_{2}$, CdSe with $4 \mathrm{~N}$-purity) were weighed in a glove box purged with nitrogen gas, and melted at $950{ }^{\circ} \mathrm{C}$ for $12 \mathrm{~h}$ in an evacuated $\left(10^{-3} \mathrm{~Pa}\right)$ silica glass tube. The melts were then quenched in cold water and for $5 \mathrm{~h}$.

X-ray diffraction (XRD) patterns were measured by an X-ray diffractometer (D/MAX 2550VB/PC, Rigaku Corporation, Japan) with the $\mathrm{Cu}-\mathrm{K} \alpha$ irradiation. High-angle-annular-dark-field scanning TEM (HAADF-STEM) was measured using FEI Talos F200x, USA, operating at $200 \mathrm{kV}$ and equipped with an energy-dispersive spectrometer (EDS) system. The elemental mapping was measured in the STEM-EDS mode [15]. Optical transmission spectra were measured by a Perkin-Elmer Lambda 950 UV-VIS spectrophotometer from 500 to $2500 \mathrm{~nm}$, and by a Bruker Tensor 27 Fourier transform infrared spectrophotometer (FTIR, Ettlingen, Germany) from 2.5 to $15 \mu \mathrm{m}$. PL spectra were measured by an Edinburgh FLS980 fluorescence spectrometer (Edinburgh Instruments), with the PL intensity corrected by the instrumental response. The excitation source was a $1570 \mathrm{~nm}$ erbium-doped fiber laser.

\section{Results and discussion}

Limited by the softening temperature of the silica glass tube $\left(1100^{\circ} \mathrm{C}\right)$, the $\mathrm{ZnSe}$ and CdSe compounds were used as the $\mathrm{Zn}$ and $\mathrm{Cd}$ metal sources. However, because the standard enthalpy of formation for $\mathrm{ZnS}(-205 \mathrm{~kJ} / \mathrm{mol})$ is greater than that of $\mathrm{ZnSe}(-170.3 \mathrm{~kJ} / \mathrm{mol})$, the former crystal is expected to grow with a larger formation probability in sulfur-containing ChG glasses upon thermal annealing [13,14]. It is indeed the case as shown in XRD spectra (Fig. 2). Several sharp diffraction peaks are superimposed on a broad amorphous background typical of nano-glass composites. Referring to the standard crystals from the Joint Committee on Powder Diffraction Standards (JCPDS), wurtzite ZnS (PDF No. 36-1450), cubic CdS (80-0019), hexagonal ZnSe (37-1463) and $\left(\mathrm{Zn}_{0.5} \mathrm{Cd}_{0.5}\right) \mathrm{S}(01-089-2943$ in Highscore software) crystals can be identified unambiguously from the ZnS, CdS, ZnSe and ZnCdS samples, respectively. The success in the formation of the ternary $\left(\mathrm{Zn}_{0.5} \mathrm{Cd}_{0.5}\right) \mathrm{S}$ crystal benefits from the complete solid solution of $\mathrm{ZnS}$ and CdS (Fig. 2(a)) [16].

In the ZnSSe sample, though its crystallographic peaks do not match any of those reference ternary $\mathrm{Zn}\left(\mathrm{S}_{\mathrm{x}} \mathrm{Se}_{1-\mathrm{x}}\right)$ crystals included in JCPDS, the crystal composition (the $x$ value) can be estimated according to
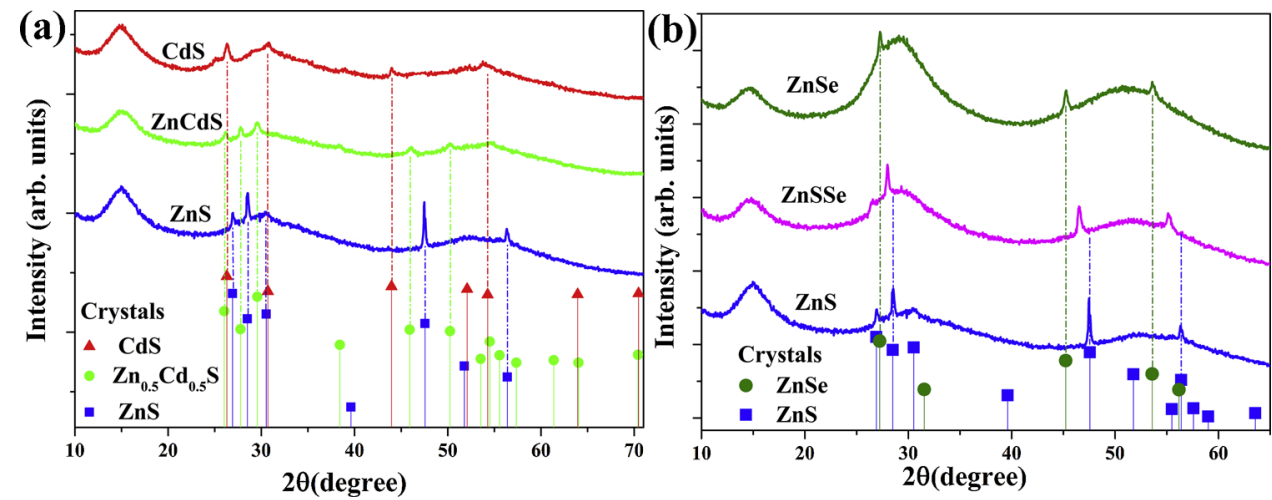

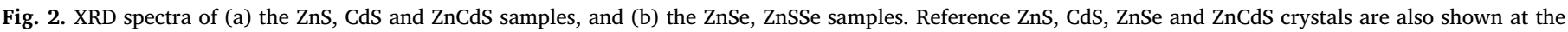
figure bottom for comparison. 
Vegard's law [17]. In the calculation, the c-axis lattice parameter is linearly dependent on the composition $x, c_{(x)}=x c_{Z n S}+(1-x) c_{Z n S e}$, where $c_{x}, c_{(Z n S)}$, and $c_{(Z n S e)}$ are the lattice parameters of $\mathrm{Zn}\left(\mathrm{S}_{\mathrm{x}} \mathrm{Se}_{1-\mathrm{x}}\right), \mathrm{ZnS}$ and $\mathrm{ZnSe}$, respectively. For the calculation, we used the diffraction peaks for the (002), (110) and (112) planes of $\mathrm{ZnS}$, which lie at $2 \theta-28.5^{\circ}, 2 \theta-47.6^{\circ}$, and $2 \theta-56.4^{\circ}$, respectively; and the diffraction peaks for the (111), (220) and (311) planes of ZnSe, which lie at $2 \theta-27.3^{\circ}, 2 \theta-45.4^{\circ}$, and $2 \theta-53.6^{\circ}$, respectively. The calculated $x$ value is 0.52 with an uncertainty of 0.02 related to the composition fluctuation within the XRD probe size $(\sim 1 \mathrm{~mm})$.

The crystallinity (volume fraction of the crystalline phase), estimated by the ratio of the crystallographic peak area to the whole XRD pattern, is a critical parameter. The larger the crystallinity, the more tetrahedral crystal sites available for the dopants $\left(\mathrm{Co}^{2+}\right)$, and thus the stronger the MIR emission. Taken as an example, the crystallinity in the ZnSSe sample is approximately $4 \%$, being four times of that found in the $\mathrm{As}_{2} \mathrm{~S}_{3}$-ZnSe nano-glass composite $(\sim 1 \%)$ [13]. We have tried to further increase the crystallinity by tuning the annealing temperature and time. It is found that the annealing temperature plays a more important role in increasing the crystallinity, but the samples with a higher crystallinity also suffer from deteriorated transparency. In this work, the annealing conditions were optimized with respect to the crystallinity and optical transparency.

The microscopic morphology of nano-composites was examined by TEM as shown in Fig. 3. In the ZnCdS sample (cation-substitution), the rod-shaped particles of $\sim 60 \mathrm{~nm}$ in width and $\sim 200 \mathrm{~nm}$ in length are distributed in the glass matrix (Fig. 3(a)). The lattice fringe as shown in Fig. 3(c) presents the interplanar spacings of 0.34 and $0.30 \mathrm{~nm}$, corresponding well to the (100) and (101) planes of wurtzite $\left(\mathrm{Zn}_{0.5} \mathrm{Cd}_{0.5}\right) \mathrm{S}$ crystal, respectively. We have previously shown that pure phase hexagonal wurtzite $\mathrm{ZnS}$ nanorods can be formed in a similar ChG glass [14]. Here, we provide important evidence that the crystal morphology is preserved in the cation-substituted ternary $\left(\mathrm{Zn}_{0.5} \mathrm{Cd}_{0.5}\right) \mathrm{S}$ NCs [16]. This is in sharp contrast to the ZnSSe sample (anion-substitution). As shown in Fig. 3(d), the ZnSSe NCs have the shape of nanorods with a number of small-sized branches that tend to form clusters. The interplanar spacings are 0.64 and $0.34 \mathrm{~nm}$ as marked in Fig. 3(f), corresponding well to the (0001) and (1010) planes of the wurtzite $\mathrm{Zn}$ $\left(\mathrm{S}_{0.51} \mathrm{Se}_{0.49}\right)$ crystal reported previously, and confirming the validity of Vegard's law [17]. In both cases of the ternary ZnCdS and ZnSSe samples, dislocation and stacking faults of the NCs can be found as illustrated in Fig. 3(b) and (e), which are caused by the lattice mismatch $[9,18]$.

The nanoscale distribution of the $\mathrm{Co}^{2+}$ dopant as well as the other elements was checked by STEM-EDS elemental mapping. The enrichment of the $\mathrm{Zn}, \mathrm{Cd}$ and Co elements in the nanorods embedded in the ZnCdS sample can be clearly seen as shown in Fig. 4. While the Ge and

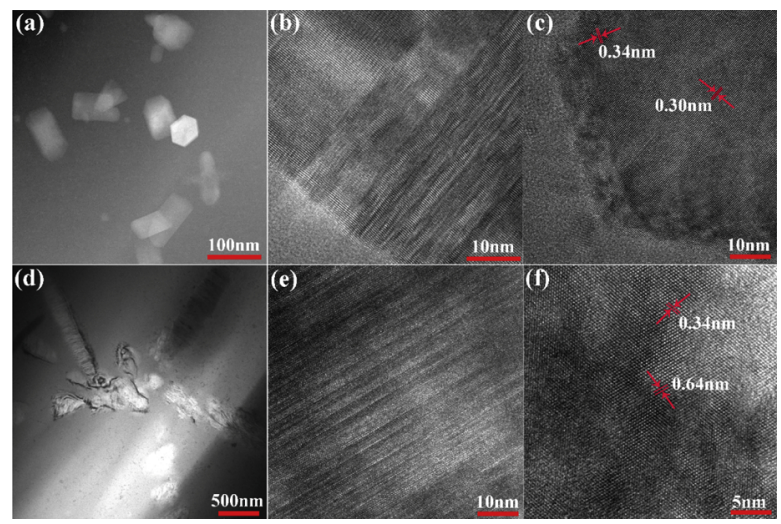

Fig. 3. TEM images of (a, b) the ZnCdS and (d, e) ZnSSe samples. HRTEM images of (c) the ZnCdS and (f) ZnSSe samples. The d-spacing are marked by lines in (c) and (f).
As elements show complementary distributions to the above elements. The results indicate that $\mathrm{Co}^{2+}$ is successfully doped into in the NCs, and the growth of the NCs is likely to be hindered by a diffusion barrier formed by the highly viscous, germanium and arsenic-enriched shell [14]. Similar results were found in the ZnSSe sample with the embedded tetrapod NCs being enriched in the Zn, S, Se and Co elements (Fig. 5).

Optical transparency is crucial for such nano-glass composites to be potentially applied to optical fibers, planar waveguides and laser gain media. Transmission spectra of samples are shown in Fig. 6. For all the samples, the transparency in the wavelength range of $0.8-5 \mu \mathrm{m}$ is over $50 \%$. The overall transparency and particularly that in the NIR range $(0.8-2 \mu \mathrm{m})$ is higher than that of $\mathrm{Cr}^{2+}$-doped nano-composites studied recently [14]. The good transparency owes its origin to the favorable refractive index matching between the ChG glass matrix and the embedded ChG crystals $(\sim 2.40)$ [19]. Three absorption bands can be observed peaking at $\sim 2800\left(\nu_{1}\right), 1550\left(\nu_{2}\right)$ and $700 \mathrm{~nm}\left(\nu_{3}\right)$, which can be assigned to the spin allowed transitions from the ${ }^{4} \mathrm{~A}_{2}(\mathrm{~F})$ ground state to the ${ }^{4} \mathrm{~T}_{2}(\mathrm{~F}),{ }^{4} \mathrm{~T}_{1}(\mathrm{~F})$ and ${ }^{4} \mathrm{~T}_{1}(\mathrm{P})$ excited states of $\mathrm{Co}^{2+}$ in tetrahedral site [9]. The crystal field splits the lowest ${ }^{4} \mathrm{~F}$ state of a free $\mathrm{Co}^{2+}$ into the ${ }^{4} \mathrm{~T}_{1}$ (F) and ${ }^{4} \mathrm{~T}_{2}$ (F) excited states and the ${ }^{4} \mathrm{~A}_{2}$ (F) ground state. The energy splitting between these ground and excited states is subjected to the crystal field strength 10Dq which can be estimated by [4]:

$D q=\frac{Q^{2} r^{4}}{24 \pi \varepsilon_{0} R^{5}}$

Where, $\mathrm{Q}$ is the charge of the ligand, $\mathrm{r}$ is the mean radius of $3 \mathrm{~d}$-electrons, $\varepsilon_{0}$ is the dielectric susceptibility and $\mathrm{R}$ is the metal ion-to-ligand distance. According to the Tanabe-Sugano (TS) diagram of tetrahedrally coordinated $\mathrm{d}^{7}$ ion (e.g., $\mathrm{Co}^{2+}$ ) (Fig. 7(b)), the energy splitting decreases with the deceasing value of Dq. The Dq and Racah B parameter, an interelectronic repulsion parameter, can be obtained by $\nu_{1} / 10$ and $\left(\nu_{2}+\nu_{3}-30 \mathrm{Dq}\right) / 15$ [20], respectively, which are $329.7 \mathrm{~cm}^{-1}$ $\left(633.6 \mathrm{~cm}^{-1}\right), 342.7 \mathrm{~cm}^{-1}\left(647.2 \mathrm{~cm}^{-1}\right), 343.3 \mathrm{~cm}^{-1}\left(643.3 \mathrm{~cm}^{-1}\right)$ and $346.8 \mathrm{~cm}^{-1}\left(666.2 \mathrm{~cm}^{-1}\right)$, for the ZnSe, ZnSSe, ZnCdS and ZnS samples. The substitutions of $\mathrm{Zn}$ and $\mathrm{S}$ by $\mathrm{Cd}$ and Se of larger ionic sizes result in smaller Dq values, and thus "red shift" in the emission band to longer wavelength is expected as indeed observed experimentally (Fig. 7(a)).

Ultra-broadband MIR emissions covering the wavelength region of 2.5-4.5 $\mu \mathrm{m}$ are observed, for the first time to our knowledge, in the $\mathrm{Co}^{2+}$-doped nano-ChG glass composites (Fig. 7(a)). The MIR emission originates from the ${ }^{4} \mathrm{~T}_{2}(\mathrm{~F}) \rightarrow{ }^{4} \mathrm{~T}_{2}(\mathrm{~F})$ transition of $\mathrm{Co}^{2+}$. Its peak wavelength can be tuned from 3.0 ( $\mathrm{ZnS}$ ) to 3.28 (ZnSSe) and 3.34 (ZnSe), and up to $3.5 \mu \mathrm{m}$ ( $\mathrm{ZnCdS}$ ) via the anion or cation substitution. The emission bandwidth defined by the full-width-at-half-maximum (FWHM) increases following the same order of the red shift in the emission band $\left(\lambda_{0}, E_{0}\right)$. The FWHM broadens from $664 \mathrm{~nm}$ in $\mathrm{ZnS}$ to $786 \mathrm{~nm}$ in ZnSSe and $846 \mathrm{~nm}$ in ZnSe, and up to $933 \mathrm{~nm}$ in ZnCdS. Generally speaking, crystals with larger lattice constants represent "soft" surroundings for the luminescent ion, and exhibiting a larger Stokes shift $(\Delta \lambda)$. This will then produce a broader absorption or emission band (larger $\Delta \mathrm{E})$ according to the expression $\left[\left(\Delta \lambda / \lambda_{0} \propto(\Delta \mathrm{E} /\right.\right.$ $\left.\mathrm{E}_{0}\right)^{1 / 2}$ ] [21]. Furthermore, the multiple crystal sites experienced by $\mathrm{Co}^{2+}$ due to CFE of the NCs can also lead to broadened emission band. Such tunable and ultra-broad MIR emissions effectively embrace a number of characteristic emissions of rare-earth (RE) ions, including $2.7 \mu \mathrm{m}$ of $\mathrm{Er}^{3+}, 2.9 \mu \mathrm{m}$ of $\mathrm{Ho}^{3+}$ and $\mathrm{Dy}^{3+}, 3.8 \mu \mathrm{m}$ of $\mathrm{Tm}^{3+}, 4.3 \mu \mathrm{m}$ of $\mathrm{Dy}^{3+}[22,23]$. The emission dip centered at $4.23 \mu \mathrm{m}$ is due to the absorption of $\mathrm{CO}_{2}$ in air. The nano-ChG glass composites present herein are potential waveguide materials for gas detection (of $\mathrm{H}_{2} \mathrm{O}$ at $2.9 \mu \mathrm{m}$, $\mathrm{NH}_{3}$ at $3.0 \mu \mathrm{m}, \mathrm{CH}_{4}$ at $3.2 \mu \mathrm{m}, \mathrm{H}_{2} \mathrm{~S}$ at $4.0 \mu \mathrm{m}, \mathrm{N}_{2} \mathrm{O}$ at $4.4 \mu \mathrm{m}$, and $\mathrm{CO}_{2}$ at $4.2 \mu \mathrm{m}$ etc.) [22].

It is interesting to note that no MIR emission is observed in the $\mathrm{Co}^{2+}$ doped CdS sample, which can be accounted for by the different doping behaviors of $\mathrm{Co}^{2+}$ in $\mathrm{ZnS}$ and CdS NCs. Previous studies have 


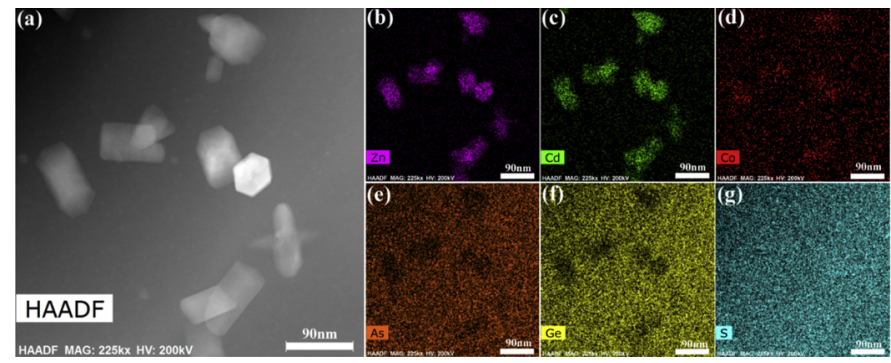

Fig. 4. (a) HAADF-STEM image of the ZnCdS sample, and its corresponding STEM-EDS elemental mappings of (b) Zn, (c) Cd, (d) Co, (e) As, (f) Ge, (g) S, with their concentrations reflected by the brightness in colors.

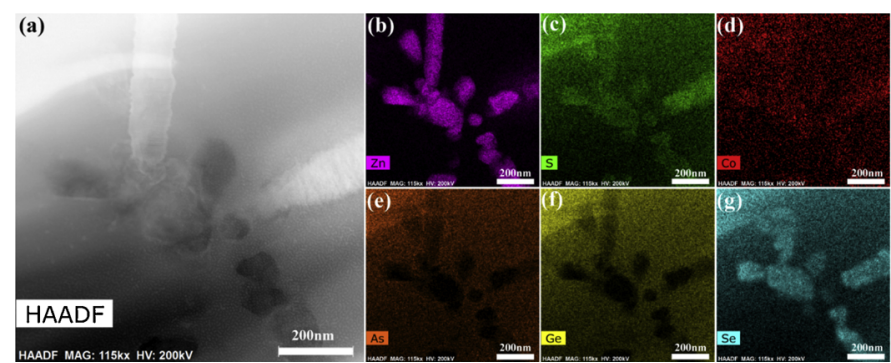

Fig. 5. (a) HAADF-STEM image of the ZnSSe sample, and its corresponding STEM-EDS elemental mappings of (b) Zn, (c) S, (d) Co, (e) As, (f) Ge, (g) Se, with their concentrations reflected by the brightness in colors.
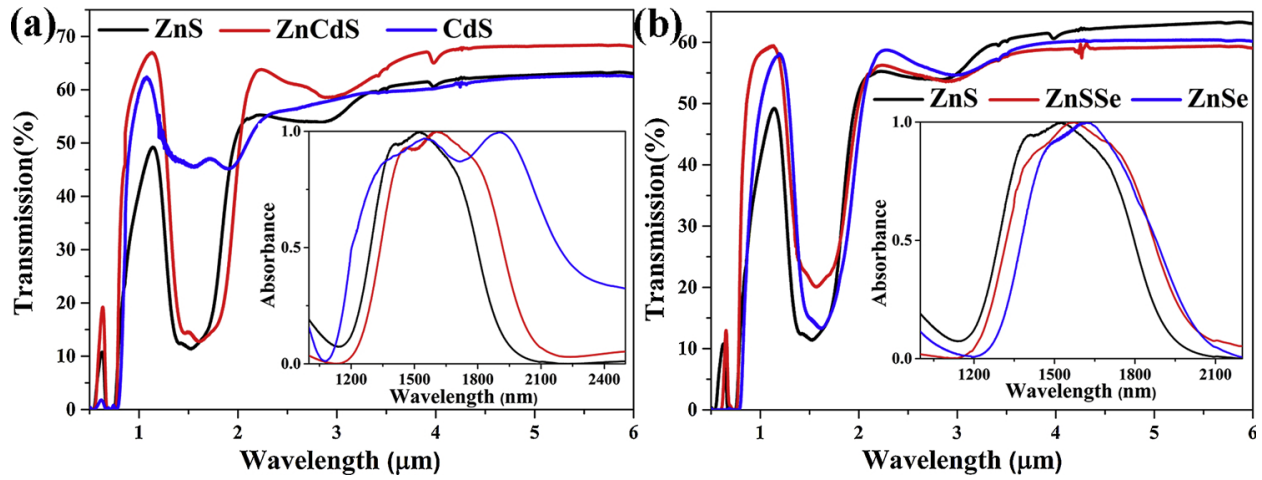

Fig. 6. Transmission spectra of (a) the ZnS, ZnCdS, and CdS samples, and (b) the ZnS, ZnSSe, ZnSe samples with a fixed thicknesses of $2.0 \mathrm{~mm}$. Insets are the expanded and normalized absorption band of $\mathrm{Co}^{2+}$.

demonstrated that the large mismatch between the ionic radii of $\mathrm{Co}^{2+}$ $(0.74 \AA)$ and $\mathrm{Cd}^{2+}(0.97 \AA)$ precludes the internal doping of $\mathrm{Co}^{2+}$ in CdS, while the similarity of $\mathrm{Zn}^{2+}(0.74 \AA)$ and $\mathrm{Co}^{2+}$ ionic radii allows isotropic incorporation of $\mathrm{Co}^{2+}$ in $\mathrm{ZnS}$ during nanocrystal growth [24]. Because $\mathrm{Co}^{2+}$ ions bond primarily to the surfaces of the CdS NCs, the spectroscopic properties of $\mathrm{Co}^{2+}$ doped CdS NCs are much more susceptible to surrounding chemical environments. For example, the absorption intensity of $\mathrm{Co}^{2+}$ in $\mathrm{CdS}$ quantum dots solution decays gradually with time because of exposure of surface-bound $\mathrm{Co}^{2+}$ ions to solvent. Similarly, because $\mathrm{Co}^{2+}$ ions tend to bond to the surface of the CdS NCs embedded in the glasses, $\mathrm{Co}^{2+}$ ions are more readily influenced by hydroxyl groups which exist as impurities known for their strong luminescence quenching effect in glasses [25].
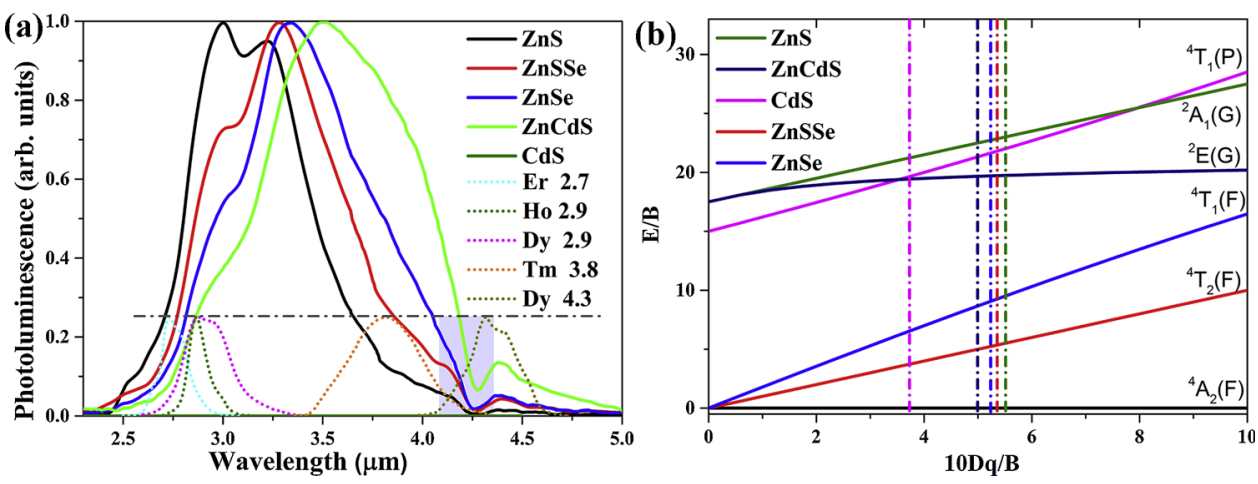

Fig. 7. (a) MIR emission spectra of the ZnS, $\mathrm{ZnSSe}, \mathrm{ZnSe}, \mathrm{ZnCdS}$, and CdS samples excited by a $1570 \mathrm{~nm} \mathrm{Er}^{3+}$-doped fiber laser $(0.6 \mathrm{~W})$. The characteristic emission spectra of some selected rare-earth ions are also included. The shaded area corresponds to the absorption band of carbon dioxide. (b) Tanabe-Sugano (TS) diagram for the tetrahedrally coordinated $\mathrm{Co}^{2+}$ in the investigated samples. 


\section{Conclusion}

A variety of $\mathrm{Co}^{2+}$-doped binary and ternary ChG NCs is thermally grown in the ChG glasses. The nano-ChG glass composites thus obtained possess good optical transparency, and show MIR emissions perfectly filling the 3-4 $\mu \mathrm{m}$ spectral gap. By adjustment of the glass compositions, the NCs embedded in the glasses can be engineered through the cationand anion-substitutions such that new ternary $\left(\mathrm{Zn}_{0.5} \mathrm{Cd}_{0.5}\right) \mathrm{S}$ and $\mathrm{Zn}$ $\left(\mathrm{S}_{0.52} \mathrm{Se}_{0.48}\right)$ ChG NCs are obtained for the first time. The composition of the $\mathrm{Zn}\left(\mathrm{S}_{0.52} \mathrm{Se}_{0.48}\right) \mathrm{NCs}$ is determined with respect to Vegard's law and finds a good agreement with the TEM data. The TEM examination also provides direct evidence that $\mathrm{Co}^{2+}$ is enriched/doped in the precipitated ChG NCs. Because of the variations in the crystal field environments surrounding $\mathrm{Co}^{2+}$, the MIR emission peak wavelength can be tuned from 3.0 up to $3.5 \mu \mathrm{m}$, and the bandwidth (FWHM) from 664 up to $933 \mathrm{~nm}$. The phenomena can be understood by referring to the changes in the crystal field strength according to the TS diagram of tetrahedrally coordinated $\mathrm{Co}^{2+}$. The CFE strategy demonstrated in this work can be extended to other ChG crystals and composites doped with $\mathrm{TM}^{2+}$ ions. It will be our next step to draw nano-ChG glass composite fibers based on the developed materials.

\section{Declaration of Competing Interest}

There are no conflicts to declare.

\section{Acknowledgement}

This work was financial supported by National Key R\&D Program of China (2016YFE0126500), National Natural Science Foundation of China (NSFC 61575050 and 51872055), the Fundamental Research Funds for the Central Universities (HEUCFG201841), the Open Fund of the State Key Laboratory on Integrated Optoelectronics (IOSKL2016KF03), Natural Science Foundation of Heilongjiang Province of China (F2017006), European Regional Development FundProject "High sensitive sensors and low density materials based on polymeric nanocomposites - NANOMAT (No. CZ.02.1.01/0.0/0.0/ 17_048/0007376)", and the 111 project (B13015) to the Harbin Engineering University.

\section{References}

[1] Q. Du, Z. Luo, H. Zhong, Y. Zhang, Y. Huang, T. Du, W. Zhang, T. Gu, J. Hu, Chipscale broadband spectroscopic chemical sensing using an integrated super-continuum source in a chalcogenide glass waveguide, Photon. Res. 6 (2018) 506-510.

[2] L.D. DeLoach, R.H. Page, G.D. Wilke, S.A. Payne, W.F. Krupke, Transition metaldoped zinc chalcogenides: spectroscopy and laser demonstration of a new class of gain media, IEEE J. Quantum Electron. 32 (1996) 885-895.

[3] S.B. Mirov, I.S. Moskalev, S. Vasilyev, V. Smolski, V.V. Fedorov, D. Martyshkin, J. Peppers, M. Mirov, A. Dergachev, V. Gapontsev, Frontiers of Mid-IR lasers based on transition metal doped chalcogenides, IEEE J. Sel. Top. Quantum Electron. 24 (2018) 1-29.

[4] A.D. Martinez, D.V. Martyshkin, R.P. Camata, V.V. Fedorov, S.B. Mirov, Crystal field engineering of transition metal doped II-VI ternary and quaternary semiconductors for mid-IR tunable laser applications, Opt. Mater. Express 5 (2015) 2036-2046.

[5] M.E. Doroshenko, V.V. Osiko, H. Jelínková, M. Jelínek, M. Němec, J. Šulc, N.O. Kovalenko, A.S. Gerasimenko, V.M. Puzikov, Spectroscopic and laser properties of $\mathrm{Cr}^{2+}$ ions in $\mathrm{Zn}_{1-\mathrm{x}} \mathrm{Mg}_{\mathrm{x}}$ Se solid solutions, Opt. Mater. 47 (2015) 185-189.

[6] M.E. Doroshenko, V.V. Osiko, H. Jelínková, M. Jelínek, J. Šulc, M. Němec, D. Vyhlídal, M. Čech, N.O. Kovalenko, A.S. Gerasimenko, Spectroscopic and laser properties of bulk iron doped zinc magnesium selenide Fe:ZnMgSe generating at 4.5-5.1 $\mu \mathrm{m}$, Opt. Express 24 (2016) 19824-19834.

[7] M.E. Doroshenko, H. Jelínková, M. Jelínek, J. Šulc, D. Vyhlídal, N.O. Kovalenko, I.S. Terzin, Room temperature $\mathrm{Fe}^{2+}: \mathrm{Cd}_{1-\mathrm{x}} \mathrm{Mn}_{\mathrm{x}} \mathrm{Te}$ laser generating at 5.4-6 $\mu \mathrm{m}$, Opt. Lett. 43 (2018) 5058-5061.

[8] N. Myoung, D.V. Martyshkin, V.V. Fedorov, S.B. Mirov, Mid-IR lasing of iron-cobalt co-doped ZnS(Se) crystals via Co-Fe energy transfer, J. Lumin. Appl. 133 (2013) $257-261$.

[9] M. Chen, X. Cui, X. Xiao, Y. Xu, J. Cui, J. Guo, C. Liu, H. Guo, Mid-Infrared Emission of Transition Metal $\mathrm{Co}^{2+}$-Doped ZnSe Nanocrystals at Room Temperature via Hydrothermal Preparation, ACS Appl. Nano Mater. 2 (2019) 2844-2853.

[10] M.A. Ali, J. Ren, T. Zhao, X. Liu, Y. Hua, Y. Yue, J. Qiu, Broad mid-infrared luminescence in a metal-organic framework glass, ACS Omega 4 (2019) 12081-12087.

[11] C. Lin, C. Rüssel, S. Dai, Chalcogenide glass-ceramics: functional design and crystallization mechanism, Prog. Mater. Sci. 93 (2018) 1-44.

[12] S.A. Lourenço, R.S. Silva, N.O. Dantas, Tunable dual emission in visible and nearinfrared spectra using $\mathrm{Co}^{2+}$-doped PbSe anocrystals embedded in a chalcogenide glass matrix, Phys. Chem. Chem. Phys. 18 (2016) 23036-23043.

[13] X. Lu, Y. Zhang, J. Ren, E. Lewis, G. Farrell, A. Yang, Z. Yang, P. Wang, Chalcogenide glasses with embedded ZnS nanocrystals: Potential mid-infrared laser host for divalent transition metal ions, J. Am. Ceram. Soc. 101 (2018) 666-673.

[14] X. Lu, Z. Lai, R. Zhang, H. Guo, J. Ren, L. Strizik, T. Wagner, G. Farrell, P. Wang, Ultrabroadband mid-infrared emission from $\mathrm{Cr}^{2+}$-doped infrared transparent chalcogenide glass ceramics embedded with thermally grown ZnS nanorods, J. Eur. Ceram. Soc. 39 (2019) 3373-3379.

[15] Z. Gao, S. Guo, X. Lu, J. Orava, T. Wagner, L. Zheng, Y. Liu, S. Sun, F. He, P. Yang, J. Ren, J. Yang, Controlling selective doping and energy transfer between transition metal and rare earth ions in nanostructured glassy solids, Adv. Opt. Mater. 6 (2018) 1701407.

[16] Y. Liu, J.A. Zapien, Y.Y. Shan, C.Y. Geng, C.S. Lee, S.T. Lee, Wavelength-Controlled Lasing in $\mathrm{Zn}_{\mathrm{x}} \mathrm{Cd}_{1-\mathrm{x}} \mathrm{S}$ Single-Crystal Nanoribbons, Adv. Mater. 17 (2005) 1372-1377.

[17] M. Wang, G.T. Fei, Y.G. Zhang, M.G. Kong, L.D. Zhang, Tunable and predetermined bandgap emissions in alloyed $\mathrm{ZnS}_{\mathrm{x}} \mathrm{Se}_{1-\mathrm{x}}$ nanowires, Adv. Mater. 19 (2007) 4491-4494.

[18] F. Huang, J.F. Banfield, Size-Dependent Phase Transformation Kinetics in Nanocrystalline ZnS, J. Am. Chem. Soc. 127 (2005) 4523-4529.

[19] K. Xia, Z. Liu, Y. Yuan, H. Chen, H. Gan, S. Dai, X. Wang, Z. Xianghua, R. Wang, Broadband mid-infrared emission from $\mathrm{Cr}^{2+}$ in crystal-in-glass composite glasses by Hot Uniaxial pressing, J. Am. Ceram. Soc. (2019) 0.

[20] M. Dondi, M. Ardit, G. Cruciani, C. Zanelli, Tetrahedrally coordinated $\mathrm{Co}^{2+}$ in oxides and silicates: Effect of local environment on optical properties, Am. Miner. 99 (2014) 1736-1745.

[21] I.T. Sorokina, K.L. Vodopyanov, Solid-State Mid-Infrared Laser Sources, Springer Science \& Business Media, 2003.

[22] J. Ari, F. Starecki, C. Boussard-Plédel, Y. Ledemi, Y. Messaddeq, J.L. Doualan, A. Braud, B. Bureau, V. Nazabal, Co-doped $\mathrm{Dy}^{3+}$ and $\mathrm{Pr}^{3+} \mathrm{Ga}_{5} \mathrm{Ge}_{20} \mathrm{Sb}_{10} \mathrm{~S}_{65}$ fibers for mid-infrared broad emission, Opt. Lett. 43 (2018) 2893-2896.

[23] C. Lin, S. Dai, C. Liu, Ba. Song, Y. Xu, F. Chen, J. Heo, Mechanism of the enhancement of mid-infrared emission from $\mathrm{GeS}_{2}-\mathrm{Ga}_{2} \mathrm{~S}_{3}$ chalcogenide glass-ceramics doped with $\mathrm{Tm}^{3+}$, Appl. Phys. Lett. 100 (2012) 231910.

[24] P.V. Radovanovic, D.R. Gamelin, Electronic Absorption Spectroscopy of Cobalt Ions in Diluted Magnetic Semiconductor Quantum Dots: Demonstration of an Isocrystalline Core/Shell Synthetic Method, J. Am. Chem. Soc. 12349 (2001) 12207-12214.

[25] Y. Chu, J. Ren, J. Zhang, L. Liu, P. Wang, J. Yang, G. Peng, L. Yuan, Effects of melting temperature and composition on spectroscopic properties of $\mathrm{Er}^{3+}$-doped bismuth glasses, Opt. Mater. Express 6 (2015) 279-287. 